DOI: http://dx.doi.org/10.4314/gjedr.v11i2.1

GLOBAL JOURNAL OF EDUCATIONAL RESEARCH VOL 11, NO. 2, 2012: 73-78

COPYRIGHT@ BACHUDO SCIENCE CO. LTD PRINTED IN NIGERIA. ISSN 1596-6224

www.globaljournalseries.com; Info@globaljournalseries.com

\title{
GESTURES IN GUIDANCE AND COUNSELLING AND THEIR PEDAGOGICAL/ANDROGOGICAL IMPLICATIONS
}

\author{
P. M. ANAKE AND L. J. ASOR \\ (Received 14, February 2012; Revision Accepted 20, June 2012)
}

\begin{abstract}
The purpose of this paper was to $x$-ray the implications of gestures, their usage and relevance in guidance and counselling. The historical background of guidance and counselling was traced and concepts like guidance, counselling and gesture were clarified. Gestures as non-verbal cues in counselling do not stand on its own but embedded in other counselling techniques used during a counselling process from the beginning to the ending of counselling interview. The various forms of gestures, uses and application and their implications were explained to illustrate how gestures can be identify, explored and utilized by the experienced guidance counsellor and a conscientiser to help his/her client during counselling interview.
\end{abstract}

\section{INTRODUCTION/HISTORICAL DEVELOPMENT}

Before the formal introduction of Guidance and Counseling, man had sought for advice from others believed to possess superior knowledge. Some people consulted traditional healers, while others consulted elders and priests. The history of modern guidance can be traced to United States of America where it was started by Frank Parson in 1908. Because of his unique efforts in pioneering the course of guidance and counselling, he is today regarded as the father of guidance. Thus guidance started as vocational guidance with Parson, (Uzoeshi, 2005). However, in Nigeria, Guidance and Counselling started in 1959 by a group of Irish religious sisters at St. Theresa's College, OkeAdo in Ibadan. They invited experts from different disciplines to advice them on the vocational placement of 60 girls who were graduating that year. This group of advisers in 1962 formed the Ibadan careers council, which later changed to Nigerian career council in 1967 (Denga, 2001). In early 70 s, Nigerian professional counsellors trained abroad started coming back to join the universities and ministries. Several efforts were made to put the different associations in existence then under one umbrella and this led to the formation of Counseling Association of Nigeria (CASSON) in December, 1976, Professor Olu Makinde of University of Ife as its first president. Guidance and counselling was included in the 1975-1980 Development Plan, and in the National Policy on Education in 1981. Today Guidance and Counselling remains a very popular discipline in schools and non-school settings.

_ Thad S. and Alex, P. (05-07-2012) retrieve says gesture is the use of movements (especially of the hands) to communicate familiar or prearranged signals. Here communication plays an integral role in how people interact with one another. Non-verbal communication shares important equally with verbal communication. Non-verbal gestures and cues use early in life, before speaking one's first words to convey specific needs to your parents. As you grow

P. M. Anake, Department of Educational Foundations-Guidance and Counselling, University of Calabar, Calabar, Nigeria

L. J. Asor, Department of Adult and Continuing Education, University of Calabar, Calabar, Nigeria 
older, your facial expressions, gestures, eye contact and even your voice help you transfer messages to the recipient (Carolyn RussellDielucas, 2011). Hence, the use of gestures in communication various from one culture to the next. In some cultures, such as those of Southern Europe and the middle east, people use the hand freely and expressively when they speak. In other cultures people use gestures less frequently and in a more subdued way. For example, nodding one's head up and down signifies agreement in western cultures, but in some part of India the gesture means the exert opposite. A common gesture used in United States - that of making a circle with the thumb and forefinger to indicate approval - is considered an insult and an obscenity in many areas of the world (retrieved 15-07-2012).

\section{Definition of terms Guidance}

Literarily, to guide means to direct or lead. Professionally, several scholars have defined it differently. To Denga (2001) it is a cluster of formalized educational services aimed at assisting an individual to attain the fullest selfdevelopment and self-realization of his potential. In the

knowledge (the teacher) to the tabula rasa (empty mind) of the leaner.

To Shertzer and Stone (1976) guidance is a process of helping individuals to understand themselves and their world. Thus guidance aims at total development of individuals and provides information to students in the areas of education, vocational and personal-social. It helps individuals understand themselves and attain fullest development and self-realization. Guidance offers a cluster of services including counselling, information, appraisal, placement, referral, follow-up and evaluation services.

\section{Counselling}

Counselling is one of the services performed under guidance. It is defined as a learning process in which a person who has problem (client) is helped by a professional (counsellor) to behave in a rewarding manner (Onomuodeke, 2003). Counselling involves a face to face interaction and person to person relationship. Counselling is aimed at assisting normal individuals overcome their stressful incapacitating situations which could be educational, vocational or personal-social in nature. Counselling processes according to
Nwachukwu (2008) include consultation, discussion, exchange of ideas, advice and decision-making. In counselling a therapeutic relationship of warmth, tolerance, respect and security is created. A prominent andragogist, Knowles (1970), see counseling as the art and science of helping the client to discover for himself the purpose and motivation that will help achieved his desired goals

Consequently, counselling is regarded as the heart of guidance as it provides a forum for interaction, a link between the client and the counsellor. Hence guidance and counselling are twin terms expected to work together in order to help an individual to find a satisfactory and effective solution to his problems.

\section{Gesture}

Hornby (2006) defined gesture as a movement that one makes with his hands, head, face or any body part to convey a particular meaning. He further described it as something that one does or says to show a particular feeling or intention. Gesture also known as non verbal clue is one of the techniques a counsellor explores and utilizes in a counselling relationship as will be fully expounded in this paper.

Similarly, Pavlovic, Sharma \& Huang (1997) defines gesture as a motion of the body or limbs expressive of sentiment or passion: any action or posture intended to express an idea or a passion, or to enforce or emphasize an argument, assertion or opinions. Thus gesture is a specific body movement that reinforces a verbal message or conveys a particular thought or emotion. Although gestures may be made with the head, shoulders or even the legs and feet, most gestures are made with the hands and arms.

Kendon (2004), defines gesture as a form of non-verbal communication in which visible actions communicate particular message, either in place or speech or together and in parallel with spoken words. Gestures include movement of the hands, face or other parts of the body. Gesture differs from physical nonverbal communication that does not communicate specific messages, such as purely expensive displays, proxemics or displays of joint attention. Gestures allow individuals to communicate a variety of feelings and thoughts, from contempt and hostility to approval and affection, often together with body language in addition to words when they speak. 
Gannon, Emmorey, Smith \& Braun (2009), defines gesture as a motion of the body or limbs expressive of sentiment of passion; any action or positive intended to express an idea or a passion, or to enforce to emphasize an argument, assertion or opinion.

Similarly, gestures, the movement of arms and hands are different from other body language in that they tend to have a far greater association with speech and language, while the rest of body indicates more general emotional state, gestures can have specific linguistic content. Hence, gestures have three phases; preparation, stroke and retraction. The real message is in the stroke, while the preparation and retraction elements consist of moving the arms to and from the result position, to and from the start and end of the stroke.

\section{Gesture in Guidance and Counselling}

Gestures are embedded in the counselling interview or process.

From the beginning of counselling session to termination, gestures or non-verbal clues take place from both the counsellor and the client to pass across meaningful messages; this though might not be done intentionally. But the counsellor utilizes it in the helping relationship.

To Njama-Abang (2002) communication does not only include words and their meaning, but posture, gesture, voice inflection and facial expressions. This implies that it involves verbal and non-verbal aspects. Words alone cannot make a good counsellor without the "body language" which often speaks louder than voice.

Nwachukwu (2008) noted that most people are good at hearing the verbal content of a language but difficult to attend to and understand the non-verbal part of what is communicated. The non-verbal part is the more important part of the message.

\section{Various forms of gestures}

The following are the various forms of gesture:

(i) Emblems;

(ii) Iconic gestures;

(iii) metaphoric gestures regulators and affect display;

(iv) beat gestures

Emblems: These are specific gestures with specific meaning that are consciously used and consciously understood. They are use as substitutes for words and are close to sign language than everyday body language. For example, holding up the hand with all fingers closed in except the index and second finger, which and spread apart can mean " $V$ for victory" or peace (if the palm is away from the body) or a rather rude dismissal if the palm is towards the body.

Iconic gestures: They are closely related to speech, illustrating what is being said, painting with the hands. For instance, when a person illustrate a physical item by using the hands to show how big or small it is. Iconic gestures are different from other gestures because they are used to show physical, concrete items.

Iconic gestures are also useful as they add detail to the mental image that the person is trying to convey, showing the first person or second person viewpoint that the person is taking. The timing of iconic gesture in synchronization with speech show whether they are unconscious or are being deliberately added for conscious effect. In an unconscious usage, the preparation for gesture will start before the words are said, while in conscious usage there is a small lag between words and gesture - which can make the speaker/counsellor appear manipulative.

Metaphoric gestures: When using metaphoric gestures, a concept is being explained. Gestures are in three-dimensional space and are to shape and idea being explained, either with specific shapes such as finger pinches and physical shaping, or more general waving of hands that symbolizes the complexity of what is being explained.

Under metaphoric gestures we have, regulators and affect displays. Regulators are used to control turn-taking in conversation, for example, in the way that a person completes what he/she is saying, may drop his/her arms, while the other person wanting to speak may raise an arm as if to grasp the way forward. Affect display is used to display emotion, from tightening of a fist to the many forms of selftouching and holding the self, covering or rubbing eyes, ears or mouth can say, "I do not want to see, hear/say this". Holding hands or the whole body can indicate anxiety as the person literally holds himself/herself. Self-preening can show a desire to be liked and can indicate desire of another. 
Beat gestures: Beat gestures are rhythmic beating of a finger, hand or arm. They can be as short as single beat or as long as needed to make a particular point. $A$ beat is a strike that creates emphasis and grabs attention. A short and single beat can mark an important point in a conversation, while repeated beats can hammer home a critical concept.

\section{Uses and application of various forms of gestures in counselling}

According to Nova Southeastern

University (retrieved 15-07-2012), non-verbal gestures are what your recipient sees, even before a single word is heard. These symbolic messages can be a visual representation of feelings, but your words convey a different message. Using non-verbal cues help express meaning, navigate difficult situations and build a better relationship for counsellor and client in a counselling setting. In line with this, the Department of Work and Organizational Psychology (2007) in a study on gesture concluded that, non-verbal behaviours play an integral role in physician - patient relations. A physician or counsellor or conscientizer who uses positive forms of non-verbal communication techniques increases client's satisfaction. However, the study did state that the physician's personal attributes plays a role in the process of counselling.

The application of emblems form of gestures in a counselling situation is seen in the body posture and gesture which reveal whether the counsellor or counselee is interested in the conversation or talk. Thus where there is an agreement in the subject at hand, the body posture of counsellor or client will be erect and confident, or the counsellor may give the client a "thumbs up" for approval. However a pause can also portray a sign of hesitance or uneasiness in certain situations. The facial expressions and eyes are monitored during counselling interview or section conveying different attitude and emotions to the client.

The iconic form of gesture in a counselling setting is use to communicate nonverbal information to the client and how the recipient receives the information. Here, the intensity, timing, pace and sounds that convey understanding are "read" by client in addition to the words that the counsellor or concientizer may use. The client will decipher and analyze the visual observations and combine those with the verbal words to see if there are inconsistence. Where the feedback is positive, it creates good rapport and confidentiality in client and counsellor relationship.

Metaphoric gestures can be apply in a counseling setting in its non-verbal communication technique to transfer information through face-to-face assisting of the client in need of help. In counselling interview, a normal pause and stuttering are normal, but some will decipher the pause as deceit. In addition, squirning and eye shifting are apparent signs of a client lying, but a pathological liar is able to maintain constant eye contact. Also in a situation where the client is anxious or tense up, the counsellor would apply therapeutic interventions to calm the clients' fear and emotions. The uses and applications of beat gestures in counselling situation help the counsellor the draws the attention of the client to the main issue in question and the important point in a conversation or interviewing section.

Summarily, for the counsellor to achieve an immediate connection with client by breaking the net between counsellor and client in counselling section using gestures should combine direct eye contact with a warm smile. Keep his/her movements and gestures to a minimum during the first stage of interview beginning stage. This will help client get acquainted to counsellor or conscientizer. Also the counsellor shoud apply his/her ability to usually communicate ideas through gestures and other forms of body expression to enhance not just the counselling section but the overall effectiveness of his skills and experiences as a therapist as well as the total personality of the person and message.

\section{The pedagogical/andragogical implications of gestures in counselling}

Pedagogy is used to refer to the art or profession of teaching. While andragogy is the art and science of helping adults learn. Reischmann (2005) defined andragogy as the science of lifelong and lifewide education/learning of adults. Adult education is focused on the practice of the educational learning of adults.

Knowles (1995) provided the most articulate expression and understanding of androgogy from the American perspective. The structure of the theory is comprised of two 
conceptual foundations: the learning theory and design theory. The learning theory is based upon the adult and his/her desire to become and/or to express themselves as a capable human being. While conceptual foundation of the design theory is based in a process, and is not dependent upon a body of content, but help the learner acquire whatever content is needed.

On this basis, the pedagogical and adrogogical implications of gesture in counselling are:

1. In counselling setting the learner or adult or client need to know reason that make sense to them, for whatever they need to learn. Gestures strength their understanding of the counsellor's verbal message.

2. The client or adult learner in counselling section have a deep need to be selfdirecting and take responsibility for themselves. Gestures technique used by counselling help pain vivid pictures in the clients' minds.

3. Adults or learners or clients enter a learning activity with a quality and volume of experience that is a resource for their own and others' learning. Here, gestures technique convey ones' feelings and attitudes more clearly than what he/she say.

4. In teaching and learning situation, the adult learner or client as the case may be is ready to learn when they experience a need to know, or be able to do, something to perform more effectively in some aspect of their life. Purposeful gestures are good outlet for the nervous energy inherent in a speaking situation or counselling section.

5. Another implication is that adults' or clients orientation to counselling is around life situations that are task, issueor problem-centred, for which they seek solutions. Gestures in counselling situation enhance clients' attentiveness and memory retention.

6. Clients or adult learners are motivated much more internally than externally. The implication for counseling using gestures technique is to help counsellor indicate the response he/she seek from clients or adult learners.

Similarly gestures provide visual supports when the counsellor address a large number of people and the entire group may not see the counsellors' eyes.

\section{CONCLUSION}

This paper traced the historical development of guidance and counselling, and went on to define terms like guidance, counselling, and gesture. Gestures in guidance and counselling and its implications was quite clarified by explaining various forms of gestures that are inter-twined with the technique of gesture or non-verbal cue.

The method of conducting an interview will be influenced to a large extent by the purpose of the interview. Some interviews are directed towards obtaining information, some primarily towards giving help, most involve a combination of the two. The aim is to obtain knowledge of the problem to be solved and sufficient understanding of the person to be helped and of the situation so that the problem can be resolved effectively. This can only be achieved by the counsellor's competence in the use of the various forms of gestures in counselling, especially his effective understanding and use of client's gestures in the counselling relationship.

\section{REFERENCES}

Thad Starner, Alex Pentland. Visual recognition of American sign language using hidden markov models. Massachusetts Institute of Technology.

Kendon, Adam., 2004. Gesture, visible action as utterance. Cambridge: Cambridge University Press.

A $\underline{a} \underline{b} \underline{c}$ XaJ, Gannon, P. J., Emmorey, K., Smith, J.

F. and Braun, A. R., 2009. Symbolic gestures and spoken language are process by a common neural system. proc Nati Acad Sci USA.

Anagbogu, M. A., 1991. "Individual Counselling: The Nigerian Perspective". In Guidance and Counselling A Realistic Approach. (pp. 80 - 88). Owerri: International Universities Press. Boston: Houghton Mifflin Co. Calabar University of Calabar Press. 
Carolyn Russell-Delucas, April., 2011. Why is non-verbal communication important? Photo credit manos crusades image by drakis from fololia.com

Denga, D. I., 2001. Guidance and Counselling in School and Non-School Settings. Port Harcourt: Double Diamond Publications.

Denga, D. I., 2001. Guidance and Counselling in School and Non-School Settings. Port Harcourt: Double Diamond Publications.

Horny, A. S., 2006. Oxford Advanced Learners Dictionary of Current English. UK: Oxford University Press.

Horny, A. S., 2006. Oxford Advanced Learners Dictionary of Current English. UK: Oxford University Press.

Knowles M. S., 1970. The Modern practice of adult education: androgogy versus pedagogy. New York: Association Press.

Knowles, M. S., 1995. Adult learning. In Craig R. L. (ed.). ASTD training and development handbook: A guide to human resource development $\left(4^{\text {th }}\right.$ ed). New York: McGraw Hill.

Njama-Abang, F. O., 2002. Guidance and Counselling A Developmental Approach. Port Harcourt: Double Diamond Publications.
Nova Southeastern University: The importance of non-verbal cues.

Nwachukwu, D. N., 2008. Guidance and Counselling Practicum.

Onomuodeke, M. A., 2003. Principles and Practice and Guidance and Counselling. Port Harcourt: Peerafi Publications.

Reischmann, J., 2005. Androgogy: History, meaning, context, function. In English. L. M. (ed.). International Encyclopedia of Adult Education. Houndsville NY: Pulgrave Macmillan. http//www.andragogy.net

Shetzer, B, and Stone, S. C., 1976. Fundamentals of Guidance. The Department of Work and Organisational Psychology (2011). Significance of gestures. University of Neuchatel.

Uzoeshi, K. C., 2005. Guidance and Counselling Foundations and Practice. Port Harcourt: Harey Publications 